\title{
Lutzomyia longipalpis (Diptera: Psychodidae) en un foco suburbano de leishmaniosis visceral en el Cañón del Chicamocha en Santander, Colombia.
}

\author{
Mónica Flórez ${ }^{1}$, Junny Patricia Martínez ${ }^{1}$, Reinaldo Gutiérrez ${ }^{3}$, \\ Katherine Paola Luna ${ }^{3}$, Víctor Hugo Serrano ${ }^{1}$, Cristina Ferro ${ }^{4}$, \\ Víctor Manuel Angulo ${ }^{3}$, Claudia Magaly Sandoval ${ }^{2,3}$

\footnotetext{
${ }^{1}$ Escuela de Biología, Universidad Industrial de Santander, Bucaramanga, Colombia.

${ }^{2}$ Secretaría de Salud de Santander, Unidad de Entomología, Laboratorio Departamental de Salud Pública, Bucaramanga, Colombia.

${ }^{3}$ Centro de Investigaciones en Enfermedades Tropicales, CINTROP, Universidad Industrial de Santander, Piedecuesta, Colombia.

${ }^{4}$ Laboratorio de Entomología, Instituto Nacional de Salud, Bogotá, D.C., Colombia
}

Introducción. Entre los años 1998-2000 la aparición de 8 casos de leishmaniosis visceral americana en niños de un asentamiento humano de reciente establecimiento en la localidad de Guatiguará del municipio de Piedecuesta (Santander Colombia), señaló la posible presencia de un ciclo de transmisión de Leishmania en dicho lugar que motivó el presente estudio entomológico.

Objetivos. Determinar frecuencia relativa en el intra y peridomicilio de Lutzomyia longipalpis y la infección natural de este vector con Leishmania spp.

Materiales y métodos. Se utilizaron para el muestreo trampas CDC intra y peridomiciliares, capturas sobre cebo humano, cebo animal y en sitios de reposo, en el periodo de mayo de 1999 a septiembre del 2000. La infección natural se determinó mediante la técnica de PCR, en pooles de hembras de Lutzomyia longipalpis.

Resultados. Se capturaron 7.391 flebótomos. La especie predominante fue Lutzomyia longipalpis (Lutz \& Neiva), con un $99,5 \%$ de las capturas. En las recolecciones con trampas de luz CDC, $L$. longipalpis tuvo una mayor frecuencia en el intradomicilio que en el peridomicilio $(p=0,0001)$. La tasa total de infección natural fue del $1,93 \%$ y se observó una correlación positiva entre los meses de mayor abundancia y el número de hembras infectadas que ingresan al domicilio.

Conclusiones. Los resultados indican que en la localidad de Guatiguará Lutzomyia longipalpis, presenta tendencias marcadas hacia el intradomicilio, lo cual tiene serias implicaciones en la transmisión por cuanto el riesgo de transmisión se ve aumentado durante los meses de mayor abundancia por el ingreso de un mayor número de hembras infectadas. Desde el punto de vista de control este comportamiento permite diseñar estrategias que disminuyan la transmisión del parásito en el interior del domicilio.

Palabras clave: leishmaniasis visceral, Lutzomyia, infección, PCR.

Lutzomyia longipalpis (Diptera: Psychodidae) at a suburban focus of visceral leishmaniasis in the Chicamocha Canyon, Santander, Colombia.

Introduction. Between 1998 and 2000, the occurrence of 8 cases of American visceral leishmaniasis in children from a recently established human settlement in Guatiguará, in the municipality of Piedecuesta (Santander, Colombia) indicated the possible presence of Leishmania transmission in this locality. This observation motivated the current entomological investigation.

Objectives. To determine the relative frequency of Lutzomyia longipalpis inside houses and outdoors, and the natural infection of this vector with Leishmania spp.

Materials and methods. CDC light traps were used for sampling inside houses and outdoors, and sand flies were collected on human volunteers and domestic animals, and in resting 
places, during the period from May 1999 through September 2000. Natural infection was determined by PCR, in pools of female Lutzomyia longipalpis.

Results: A total of 7,391 phlebotomine sand flies were collected. The predominant species was Lutzomyia longipalpis (Lutz \& Neiva), representing $99.5 \%$ of captures. In the sand flies collected with CDC light traps, $L$. longipalpis was more frequently collected indoors than outdoors $(p=0.0001)$. The total rate of natural infection was $1.93 \%$ and a positive correlation was observed between months with higher abundance and the number of infected females entering human dwellings.

Conclusions: The results indicate that in Guatiguará Lutzomyia longipalpis, shows marked tendency for the indoors, which has important implications for leishmaniasis transmission. Furthermore, transmission risk is increased during the months of higher abundance due to the entry of a higher number of infected females. From the standpoint of control, this behaviour permits the design of strategies to reduce indoor transmission.

Key words: leishmaniasis, visceral; Lutzomyia, infection, PCR.

En América, Lutzomyia longipalpis (Lutz \& Neiva, 1912) es el principal vector de Leishmania infantum, parásito causal de la leishmaniosis visceral americana (1-3). Sin embargo, los estudios realizados en Colombia y Venezuela en 1990 y 1993, respectivamente, han comprobado que Lutzomyia evansi (Nuñez-Tovar, 1924) juega un papel importante en la transmisión de esta enfermedad en algunas áreas endémicas (4-6).

L. longipalpis se halla principalmente en áreas de bosque seco tropical (bs-T), muy seco tropical (bms-T), áridas y semiáridas; también, se ha encontrado en zonas muy húmedas y boscosas como en la ribera del río Amazonas (7). Su distribución geográfica va desde los $20^{\circ} \mathrm{N}$ en México hasta los $28^{\circ} \mathrm{S}$ en Argentina, incluyendo países como Guatemala, Costa Rica, Honduras, Colombia, Venezuela, Brasil, Paraguay y Bolivia. En Suramérica, la mayoría de los casos de leishmaniosis visceral americana proceden del noreste del Brasil y Venezuela en áreas de bosque seco tropical (bs-T) (6). El vector está aparentemente ausente en Ecuador, Perú y Chile en donde no se conocen casos de la enfermedad $(2,8,9)$.

En Colombia, L. longipalpis se ha reportado en áreas rurales con bosque seco tropical en el valle del río Magdalena en los departamentos de

\section{Correspondencia}

Mónica Flórez, Centro de Investigaciones en Enfermedades Tropicales, CINTROP, km 2 vía EI Refugio, sede UISGuatiguará, Piedecuesta, Santander, Colombia.

Teléfono: 655 0800, extensión 4026; fax: (7) 6540177 monicaflorezm@hotmail.com, cintrop@hotmail.com

Recibido: 10/08/05; aceptado: 01/02/06
Santander, Cundinamarca, Tolima y Huila y también en la Costa Caribe en los departamentos de Córdoba, Sucre y Bolívar, donde comparte su distribución con $L$. evansi, vector secundario de leishmaniasis visceral americana. También, se ha reportado en bosque húmedo tropical en áreas de leishmaniasis cutánea $(8,10,11)$.

En la vereda Guatiguará (Piedecuesta, Santander), localizada en un valle situado entre dos mesetas con elevaciones entre 930 y 1.300 msnm, a partir de 1997 se dio un rápido incremento en el número de habitantes por la agregación de familias provenientes de zonas en conflicto o de escasos recursos económicos; en el lugar se registraron ocho casos de leishmaniasis visceral americana diagnosticados en el Hospital Universitario Ramón González Valencia (Unidad de Oncología Pediátrica) en niños menores de siete años, en un periodo de tres años. El parásito se aisló en 6 de los 8 casos y se identificó como Leishmania donovani por medio de PCR múltiplex (12) (CINTROP, datos sin publicar).

Como vector se considera a $L$. longipalpis, especie ampliamente distribuida en esta zona y, como antecedente importante, se encuentra la descripción de un antiguo foco de leishmaniasis visceral americana rural de baja prevalencia, establecido en este valle, perteneciente a la jurisdicción del municipio de Girón (Palogordo) a pocos kilómetros del área de estudio y descrito en 1986 (Angulo V, Tovar E, Casas M, Cortés J. Estudio clínico-epidemiológico de la leishmaniasis visceral en Santander. Bucaramanga: UIS, 1986. p.62). 
La necesidad de estudios entomológicos que permitieran ampliar el conocimiento de la ecología y el comportamiento de las poblaciones de $L$. longipalpis en el asentamiento suburbano de Piedecuesta, Santander, con el fin de proponer estrategias de control de la transmisión de la enfermedad, motivaron la realización de este estudio que tuvo como objetivos determinar la frecuencia relativa en el intradomicilio y peridomicilio de $L$. longipalpis y la tasa de infección natural con Leishmania spp. de este vector.

\section{Materiales y métodos}

\section{Área de estudio}

Está localizada en el valle de Guatiguará sobre las laderas que lo limitan, con variaciones altitudinales entre los 930 y los 1.300 msnm. Está situado a una latitud $07^{\circ} 00^{\prime} 00^{\prime \prime} \mathrm{N}$ y longitud $73^{\circ} 05^{\prime} 20^{\prime \prime} \mathrm{W}$; por el este limita con el casco urbano del municipio de Piedecuesta (Santander), aproximadamente a $4 \mathrm{~km}$; por el oeste, con la ciudad de Girón a 16 km, y por el noroeste, con Floridablanca a $9 \mathrm{~km}$, aproximadamente.

La zona está clasificada como bosque seco tropical (bs-T) (13) con humedad relativa del $85 \%$, pluviosidad media anual de $1.700 \mathrm{~mm}$, temperatura media anual de $22,6^{\circ} \mathrm{C}$ (Base de datos. Instituto de Estudios Ambientales Metereológicos. Bucaramanga: IDEAM; 2000). Las viviendas de la vereda de Guatiguará se encuentran concentradas en un área de aproximadamente $4-5 \mathrm{~km}^{2}$, con parcelas en las que sus habitantes cultivan en mayor o menor grado piña, yuca y maracuyá; se mantienen en algunos sectores fragmentos de vegetación nativa.

A partir de 1997 se inició una migración masiva de familias a la zona, cuya población total ha ido aumentado hasta reportar en el último censo realizado en el 2000, 2.019 personas distribuidas en 622 viviendas, de las cuales, $24,2 \%$ son niños menores de siete años. También, se registró una población canina de 392 perros, aproximadamente (Secretaría de Salud de Santander. Base de datos, censo de la vereda Guatiguará, Piedecuesta, Santander, 2000). Las viviendas de la zona están construidas con diversos materiales como plástico, metal y madera y, en menor proporción, de ladrillo, tejas de zinc o eternit; la mayoría de las viviendas no cuentan con servicios sanitarios básicos.

La edad de los pacientes diagnosticados como positivos para leishmaniosis visceral americana fluctuó entre los 5 meses y los 7 años de edad. Márquez (14) encontró en esta localidad una prevalencia de infección por Leishmania donovani en perros del $47 \%(47 / 100)$. No se han reportado casos de leishmaniosis cutánea o mucocutánea en el área de estudio.

\section{Métodos de captura}

Se seleccionaron cuatro viviendas para las capturas de flebótomos, por antecedentes de casos de leishmaniasis visceral americana, por positividad para flebótomos según muestreo preliminar, alta abundancia que permitiría el muestreo en ambas laderas del valle, y consentimiento de la familia para la instalación y cuidado de las trampas. Los flebótomos se recolectaron dos veces al mes en el período comprendido entre mayo de 1999 y mayo del 2000 , extendiéndose a dos viviendas más de junio a septiembre del 2000 .

Las capturas se realizaron a nivel intra y peridomiciliario (5 -7 $\mathrm{m}$ fuera de la vivienda) con trampas de luz tipo CDC miniatura de las 19:00 a las 05:00 horas, en el peridomicilo con aspiración manual sobre cebo humano entre las 19:00 y las 20:30 horas, sobre cebo animal durante los primeros cuatro meses en gallinero y durante once meses sobre perro en el horario de las 18:30 a 21:00 horas. También se realizaron capturas en sitios de reposo como grietas de rocas, alrededor de las viviendas seleccionadas para el muestreo durante dos meses.

\section{Determinación taxonómica}

Parte de la muestra se utilizó para la identificación de las especies; después de la captura los flebótomos se preservaron en alcohol de $70^{\circ}$, se aclararon con hidróxido de potasio al $10 \%$ y fenol líquido; a las hembras se les aplicó la técnica de disección de genitalia descrita por Marcondes (15) y se utilizó la clave de Young y Duncan para su identificación (16). 


\section{Infección natural}

Para el estudio de infección natural se seleccionaron hembras de L. longipalpis que aún se encontraron vivas al llegar al laboratorio, las cuales se identificaron por caracteres morfológicos de cabeza y tórax y la confirmación de la especie se realizó mediante la extracción de la espermateca, con ayuda de alfileres entomológicos y observación al microscopio (40X) sobre una lámina portaobjeto con una gota de solución tampón, Tris $10 \mathrm{mM}$, pH 8,0 y EDTA $1 \mathrm{mM}, \mathrm{pH}$ 8,0 inmediatamente se confirmaba la especie, se almacenaban en un vial, con $20 \mu \mathrm{l}$ de la misma solución tampón y se conservaron $\mathrm{a}-20^{\circ} \mathrm{C}$.

Se conformaron grupos, cada uno con 5 hembras, en promedio, organizadas por mes y por método de captura. La extracción de ADN se realizó mediante el uso de la resina Cheelex 100 al $5 \%$ y se utilizaron un par de oligonucleótidos que se unen al origen de la replicación de ambas hebras de las moléculas del minicírculo del ADN mitocondrial amplificando una región conservada de 120 pares de bases para todas las especies de Leishmania del nuevo mundo: OL1 GGG GAG GGG CGT TCT GCG AA y OL2 CCG CCC CTA TTT TAC ACC AAC CCC (17-20, Sandoval CM, Gutiérrez R, Cárdenas R, Cabrera OL, Ferro C. Estandarización de la técnica de reacción en cadena de la polimerasa para estudios de infección natural de Lutzomyia (Diptera: Psychodidae). Biomédica 1999;19:122). La reacción de amplificación se llevó a cabo en un volumen final de $25 \mu \mathrm{l}$ que contenía 200 ng de oligonucleótidos, $1 X$ solución tampón de la Taq polimerasa (Perkin Elmer), 0,2 mM dNTP, 0,5 U Taq polimerasa (Promega), $2 \mathrm{mM} \mathrm{MgCl}_{2}$ y $2 \mu \mathrm{l} \mathrm{ADN}$. La mezcla fue puesta en un termociclador (Minicycler TM PTC-150 MJ Research) con un paso inicial de denaturación del $A D N$ a $94^{\circ} \mathrm{C}$ por 4 minutos, seguido de 30 ciclos así: a $94^{\circ} \mathrm{C}(30 \mathrm{~s}), 55^{\circ} \mathrm{C}(30$ $\mathrm{s}), 72^{\circ} \mathrm{C}(30 \mathrm{~s})$. El control positivo fueron especímenes obtenidos de la infección experimental de L. longipalpis y como control negativo, machos de la misma especie. Para la visualización de los productos de amplificación se utilizaron geles de poliacrilamida al $6 \%$ coloreados con nitrato de plata.

\section{Preparación de controles positivos para la $P C R$, infección experimental}

Ciento ochenta hembras de L. Iongipalpis, procedentes de una colonia mantenida en el Instituto Nacional de Salud, se alimentaron a través de una membrana de pollo con una suspensión 1:1 de parásitos y eritrocitos. Los parásitos, promastigotes de Leishmania infantum en una concentración $1 \times 10^{6}$, cultivados en medio $\mathrm{SBF}+\mathrm{LIT}$ a $30^{\circ} \mathrm{C}$, provenían de un aislamiento de un caso clínico comprobado de leishmaniosis visceral proveniente del foco de estudio, caracterizado por PCR multiplex.

La mezcla de parásitos y sangre se colocó en un frasco plástico con una membrana de pollo en uno de sus extremos. Luego, este frasco se colocó en la jaula de una malla muy fina (muselina) que contenía las hembras de L. longipalpis durante una hora para que se alimentaran. La mitad de la jaula se cubrió con una tela color negro y el frasco se mantuvo rodeado con la mano, fuera del alcance de los insectos, durante el tiempo que se alimentaban las hembras (1 hora) (21). Las hembras alimentadas se dejaron en la jaula de tul, con un algodón húmedo y otro con azúcar, en un insectario con una temperatura de $28^{\circ} \mathrm{C}$ y una humedad relativa del $90 \%$. Siete días después de la comida infectiva, las hembras sobrevivientes se agruparon en parejas, resuspendidas en $20 \mu \mathrm{l}$ de TE y a $-20^{\circ} \mathrm{C}$ hasta la realización de la técnica de PCR.

\section{Análisis estadístico}

Se usó la prueba T de Student para comparar la frecuencia de $L$. longipalpis capturados con los tres diferentes cebos. Para establecer alguna asociación entre la abundancia estacional de hembras de $L$. longipapis Vs. la abundancia de hembras infectadas en el intradomicilio y peridomicilio, capturadas con trampas de luz CDC, se utilizó el método de correlación, empleando el programa Statistica for Windows, release 6.0 (Statsoft, Inc., 1997).

\section{Aspectos éticos}

En esta investigación no se manipularon muestras biológicas de origen humano y las personas que participaron como cebos utilizaron pantalón y 
camisa de manga larga, y los flebótomos se capturaron sobre las ropas. Para el muestreo de flebótomos en la vivienda se solicitó el consentimiento verbal de las familias y éstas fueron protegidas por toldillos sin insecticida, para evitar sesgo en el tiempo de muestreo.

Una vez terminado el estudio a todas las familias de la localidad que tenían niños menores de 7 año les fueron entregados toldillos impregnados con insecticida, donados por el Programa Enfermedades Transmitidas por Vectores de la Secretaría de Salud de Santander.

En todos los procedimientos de laboratorio se tuvo en cuenta la Resolución No. 008430 de 1993 del Ministerio de Salud de la República de Colombia Título IV, en su Capítulo I, sobre la bioseguridad de la investigación y el manejo de material biológico que pueda contener microorganismos patógenos en los artículos 63 a 67 (literal c) y 69 .

\section{Resultados}

\section{Composición de especies}

Se realizaron 58 muestreos en los que se capturaron 7.391 flebótomos. Las especies de flebótomos registradas fueron: Lutzomyia longipalpis, Lutzomyia gomezi (Nitzulescu, 1931), Lutzomyia ovallesi (Ortiz, 1952), Lutzomyia dubitans (Sherlock, 1962), Lutzomyia camposi (Rodríguez, 1952) y un ejemplar del género Brumptomyia. L. Iongipalpis, con $99,5 \%$, fue la especie predominante; la proporción de sexos fue de 4,5 a $1(81,8 \%$ o y $18,2 \%$ \% $)$, seguida de $L$. gomezi $(0,43 \%)$; las otras especies se encontraron en menor proporción (cuadro 1).

\section{Frecuencia relativa de especies según los métodos de captura}

Capturas con trampas de CDC. De 3.174 ejemplares, $2.216(69,82 \%)$ se capturaron en el intradomicilio y $958(30,18 \%)$ en el peridomicilio. Del total de ejemplares capturados, L. longipalpis fue la especie predominante $(99,31 \%)$; se encontró con mayor frecuencia en el intradomicilio $(69,28 \%)$ que en el peridomicilio $(30,18 \%)(p=0,0001)$. En el intradomicilio, $28,34 \%$ de los individuos de $L$. longipalpis capturados con este método fueron hembras y en el peridomicilio, 35,18\%. La proporción de $\sigma^{*}:$ ? de L. longipalpis en el intradomicilio fue de 2,5 a 1 , mayor que la encontrada en el peridomicilio (1,8 a 1$)$. Todas las especies registradas en la zona ingresaron al ambiente intradomiciliario, a excepción de $L$. camposi, la cual se encontró sólo en el peridomicilio (cuadro 2).

\section{Capturas con cebo humano}

De 2.374 individuos capturados con este método, $99,45 \%$ eran $L$. longipalpis $(7,54 \%$ \% y los demás correspondieron a L. gomezi $(0,55 \%)$. La proporción de $\sigma^{*}:$ o de $L$. longipalpis fue de 12 a 1 (cuadro 2).

\section{Capturas con cebo animal}

Se recolectaron sobre gallina 1.458 ejemplares, todos pertenecientes a $L$. longipalpis $(9,81 \%$ o $)$. Sobre perro se capturaron 376 flebótomos, de los cuales, 99,4\% correspondían a L. longipalpis $(12,5 \%$ \% ) y $2(0,53 \%)$ correspondieron a $L$. gomezi. La proporción de $\sigma^{*}:$ ? de L. longipalpis sobre gallina fue de 9,2:1 y sobre perro, de 6,96: 1

Cuadro 1. Composición de especies de flebótomos en la vereda Guatiguará, Piedecuesta, Santander.

\begin{tabular}{lrrrrrr}
\hline Especie & \multicolumn{2}{c}{ Hembras } & \multicolumn{2}{c}{ Machos } & \multicolumn{2}{c}{ Total } \\
& $\mathbf{n}$ & $\mathbf{0}$ & $\mathbf{n}$ & $\mathbf{0}$ & $\mathbf{n}$ \\
\hline L. longipalpis & 1.337 & 18,18 & 6.017 & 81,82 & 7.354 & 99,50 \\
L. gomezi & 24 & 75,00 & 8 & 25,00 & 32 & 0,43 \\
L. ovallesi & 2 & 100,00 & 0 & 0,00 & 2 & 0,03 \\
L. dubitans & 1 & 100,00 & 0 & 0,00 & 1 & 0,01 \\
L. camposi & 1 & 100,00 & 0 & 0,00 & 1 & 0,01 \\
Brumptomyia sp & 0 & 0,00 & 1 & 100,00 & 1 & 0,01 \\
Total & $\mathbf{1 . 3 6 5}$ & $\mathbf{1 8 , 4 7}$ & $\mathbf{6 . 0 2 6}$ & $\mathbf{8 1 , 5 3}$ & $\mathbf{7 . 3 9 1}$ & $\mathbf{1 0 0}$ \\
\hline
\end{tabular}


Cuadro 2. Frecuencia de flebótomos según el método de captura por sexo en la vereda Guatiguará, Piedecuesta, Santander.

\begin{tabular}{|c|c|c|c|c|c|c|c|c|}
\hline \multirow[b]{2}{*}{ Especie } & \multirow[b]{2}{*}{ Sexo } & \multirow[b]{2}{*}{$\begin{array}{c}\text { CDC } \\
\text { intra } \\
n \%\end{array}$} & \multirow[b]{2}{*}{$\begin{array}{l}\text { CDC } \\
\text { peri } \\
n \%\end{array}$} & \multirow[b]{2}{*}{$\begin{array}{c}\text { Cebo } \\
\text { humano } \\
\text { n } \%\end{array}$} & \multicolumn{2}{|c|}{ Cebo animal } & \multirow[b]{2}{*}{$\begin{array}{c}\text { Reposo } \\
\text { n \% }\end{array}$} & \multirow[b]{2}{*}{$\begin{array}{l}\text { Total } \\
\text { n \% }\end{array}$} \\
\hline & & & & & $\begin{array}{c}\text { sobre } \\
\text { perro } \\
\text { n } \%\end{array}$ & $\begin{array}{c}\text { sobre } \\
\text { gallina } \\
n \%\end{array}$ & & \\
\hline \multirow[t]{2}{*}{ L. longipalpis } & $\mathrm{H}$ & $\begin{array}{c}628 \\
(28,34)\end{array}$ & $\begin{array}{c}337 \\
(35,18)\end{array}$ & $\begin{array}{c}179 \\
(7,54)\end{array}$ & $\begin{array}{c}47 \\
(12,50)\end{array}$ & $\begin{array}{c}143 \\
(9,81)\end{array}$ & $\begin{array}{c}3 \\
(33,3)\end{array}$ & $\begin{array}{r}1337 \\
(18,09)\end{array}$ \\
\hline & $M$ & $\begin{array}{c}1571 \\
(70,89)\end{array}$ & $\begin{array}{c}616 \\
(64,30)\end{array}$ & $\begin{array}{c}2182 \\
(91,91)\end{array}$ & $\begin{array}{c}327 \\
(86,97)\end{array}$ & $\begin{array}{c}1315 \\
(90,19)\end{array}$ & $\begin{array}{c}6 \\
(66,7)\end{array}$ & $\begin{array}{c}6017 \\
(81,41)\end{array}$ \\
\hline \multirow[t]{2}{*}{ L. gomezi } & $\mathrm{H}$ & $\begin{array}{c}6 \\
(0,27)\end{array}$ & $\begin{array}{c}3 \\
(0,31)\end{array}$ & $\begin{array}{c}13 \\
0,55\end{array}$ & $\begin{array}{c}2 \\
(0,53)\end{array}$ & $\begin{array}{c}0 \\
(0)\end{array}$ & $\begin{array}{c}0 \\
(0)\end{array}$ & $\begin{array}{c}24 \\
(0,32)\end{array}$ \\
\hline & M & $\begin{array}{c}8 \\
(0,36)\end{array}$ & $\begin{array}{c}0 \\
(0)\end{array}$ & $\begin{array}{c}0 \\
(0)\end{array}$ & $\begin{array}{c}0 \\
(0)\end{array}$ & $\begin{array}{c}0 \\
(0)\end{array}$ & $\begin{array}{c}0 \\
(0)\end{array}$ & $\begin{array}{c}8 \\
(0,11)\end{array}$ \\
\hline L. ovallesi & $\mathrm{H}$ & $\begin{array}{c}1 \\
(0,05)\end{array}$ & $\begin{array}{c}1 \\
(0,10)\end{array}$ & $\begin{array}{c}0 \\
(0)\end{array}$ & $\begin{array}{c}0 \\
(0)\end{array}$ & $\begin{array}{c}0 \\
(0)\end{array}$ & $\begin{array}{c}0 \\
(0)\end{array}$ & $\begin{array}{c}2 \\
(0,03)\end{array}$ \\
\hline L. dubitans & $\mathrm{H}$ & $\begin{array}{c}1 \\
(0,05)\end{array}$ & $\begin{array}{c}0 \\
(0)\end{array}$ & $\begin{array}{c}0 \\
(0)\end{array}$ & $\begin{array}{c}0 \\
(0)\end{array}$ & $\begin{array}{c}0 \\
(0)\end{array}$ & $\begin{array}{c}0 \\
(0)\end{array}$ & $\begin{array}{c}1 \\
(0,01)\end{array}$ \\
\hline L. camposi & $\mathrm{H}$ & $\begin{array}{c}0 \\
(0)\end{array}$ & $\begin{array}{c}1 \\
(0,10)\end{array}$ & $\begin{array}{c}0 \\
(0)\end{array}$ & $\begin{array}{c}0 \\
(0)\end{array}$ & $\begin{array}{c}0 \\
(0)\end{array}$ & $\begin{array}{c}0 \\
(0)\end{array}$ & $\begin{array}{c}1 \\
(0,01)\end{array}$ \\
\hline Brumptomyia sp. & M & $\begin{array}{l}10,05 \\
(0,05)\end{array}$ & $\begin{array}{l}00 \\
(0)\end{array}$ & $\begin{array}{l}00 \\
(0)\end{array}$ & $\begin{array}{l}00 \\
(0)\end{array}$ & $\begin{array}{l}00 \\
(0)\end{array}$ & $\begin{array}{l}00 \\
(0)\end{array}$ & $\begin{array}{l}10,01 \\
(0,01)\end{array}$ \\
\hline TOTAL & & 2.216 & 958 & 2.374 & 376 & 1.458 & 9 & 7.391 \\
\hline
\end{tabular}

$\mathrm{H}$ : hembra; M: macho; peri: peridomicilio; intra: intradomicilio

(cuadro 2). Al comparar la frecuencia de $L$. longipalpis capturada sobre perro, cebo humano y gallina durante cuatro meses de muestreo, se observó que sobre gallina, la frecuencia era significativamente mayor que sobre perro $(p=0,003)$, en contraste a lo obtenido con cebo humano, en el que la diferencia no era significativa $(p=0,26)$.

\section{Capturas en reposo}

Se recolectaron 9 individuos de L. longipalpis, de los cuales, 3 eran hembras.

\section{Infección natural}

Se procesaron 1.138 hembras de L. longipalpis, que correspondieron al $85 \%$ de las capturadas durante todo el año de muestreo. Con estas hembras se conformaron 240 grupos. En total, 22 grupos resultaron positivos para Leishmania spp., para una tasa de infección natural del foco de $1,93 \%$, asumiendo una hembra infectada con Leishmania spp. en cada grupo positivo. EI porcentaje de infección natural, según el tipo de muestreo, se describe en el cuadro 3 . En la figura 1 se muestra el producto esperado en 120 pares de bases, después de la amplificación con los iniciadores OL1-OL2.

\section{Dinámica de la infección natural a lo largo del año}

Se encontró, en 10/13 meses de muestreo con todos los métodos de captura, por lo menos, un grupo positivo tanto en el intra como en el peridomicilio. En general, los meses con mayor número de grupos positivos fueron junio, julio y septiembre.

En las capturas realizadas en el intradomicilio con trampas de luz CDC, se detectaron hembras infectadas durante los meses de mayo, junio, julio, septiembre y octubre del 1999 que, en su mayoría, correspondieron a meses secos, excepto septiembre. Los meses con mayor abundancia de $L$. longipalpis se correlacionaron positiva y significativamente con los picos de hembras infectadas $(r=0,645741, p=0,017)$; en este ambiente, el número de hembras/trampa/ noche fluctuó entre 0,5 y 18,17 y el número de hembras infectadas/trampa/noche entre 0,66 y 1 (figura 2A). 
Cuadro 3. Porcentaje de infección natural de Lutzomyia longipalpis, según el método de muestreo.

\begin{tabular}{lcccccc}
\hline & CDC & CDC & Cebo & \multicolumn{2}{c}{ Cebo animal } & \multirow{2}{*}{ Total } \\
\cline { 6 - 7 } & intra & peri & humano & gallina & perro & \\
\hline Grupos & 100 & 61 & 40 & 28 & 10 & 240 \\
Hembras & 504 & 290 & 168 & 135 & 38 & 1138 \\
Grupos positivos & 8 & 5 & 5 & 1 & 2 & 22 \\
Infección natural $(\%)^{*}$ & $\mathbf{1 , 5 8}$ & $\mathbf{1 , 7 2}$ & $\mathbf{2 , 9 8}$ & $\mathbf{0 , 7 4}$ & $\mathbf{5 , 2 6}$ & $\mathbf{1 , 9 3}$ \\
\hline
\end{tabular}

Intra: intradomicilio; peri: peridomicilio.

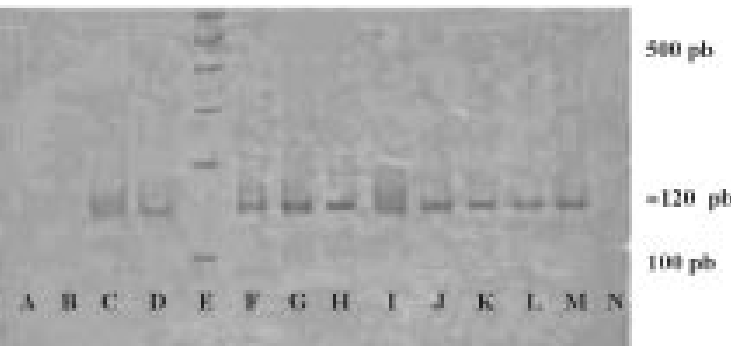

Figura 1. Determinación de la infección natural en Lutzomyia longipalpis mediante la PCR con iniciadores universales OL1 y OL2 que amplifican la región conservada del kADN en gel de poliacrilamida. Banda esperada de $\approx 120 \mathrm{pb}$. A. Control de reacción. B. Control negativo, machos de $L$. longipalpis. C. Control positivo, ADN de Leishmania chagasi. D. Control positivo, hembras de L. longipalpis infectadas. E. Peso molecular. Muestras de hembras de $L$. longipalpis, según método de captura: positivas: F. CDC, intradomicilio. G. CDC, intradomicilio. H. CDC, peridomicilio. I. CDC, peridomicilio. J. Cebo humano. K. Cebo animal, gallinero. L. Cebo animal, perro. M. Reposo: negativas: N. CDC, intradomicilio.

En el peridomicilio se detectaron hembras infectadas durante los meses de junio, julio y septiembre de 1999, enero y abril de 2000 . El número de hembras/trampa/noche para este ambiente osciló entre 0,75 y 14 y el número de hembras infectadas/trampa/noche entre 0,5 y 1 . Los meses de mayor abundancia no estuvieron correlacionados con los picos de hembras infectadas $(r=0,262375, p=0,3865)$ (figura 2B). En los meses de noviembre, diciembre y febrero no se detectó infección natural. Los valores mensuales de precipitación de la zona oscilaron entre 57 y $274 \mathrm{~mm}$ y se graficaron divididos en 10.

\section{Discusión}

La notable predominancia de L. Iongipalpis $(99,5 \%)$ en la zona concuerda con la de otros focos de leishmaniosis visceral en América: 96\% de abundancia relativa reportado en Los Yungas (Bolivia); $75,12 \%$ en la isla de Marajó (Brasil); $86,1 \%$ en El Callejón (Cundinamarca, Colombia), y en Las Marías Pavana (Choluteca, Honduras); $88,32 \%$, en Nisia Floresta (Brasil); $90,96 \%$, en Brasilito (Costa Rica); 69,6\% al nordeste del estado de Maranhao (Brasil) y $92,6 \%$ en Jacobina (Bahía, Brasil) $(3,9,22-27)$. Sin embargo, se han descrito ciertos focos endémicos para la enfermedad donde esta especie no es la predominante, sustentado con el hallazgo de otras especies del género Lutzomyia infectadas naturalmente con $L$. infantum, lo que sugiere la participación de éstas en la dinámica de la transmisión, como L. evansi en Colombia (San Andrés de Sotavento, Córdoba) (4), Venezuela (Aragua y Trujillo) $(5,28)$, Lutzomyia antunesi (29) y Lutzomyia cruzi en Brasil (30).

La fauna acompañante de $L$. longipalpis en este foco de Guatiguará difiere en frecuencia y composición respecto a los demás focos en los que la leishmaniasis visceral americana es endémica; aunque comparte algunas especies con los focos colombianos de El Callejón, Cundinamarca, y de Girón, Santander, y con el foco venezolano de Guayabita, Aragua $(3,5)$ en los cuales $L$. gomezi se presenta en muy bajas proporciones junto con altas proporciones de $L$. longipalpis. Esta asociación también se ha observado en otros focos como el de Las Marías Pavana en Choluteca, Honduras, y el de Brasilito en Costa Rica $(9,25)$.

De acuerdo con las observaciones realizadas por otros autores, la proporción de machos respecto a la de hembras de $L$. longipalpis en la localidad de estudio fue mayor con todos los métodos de 
A

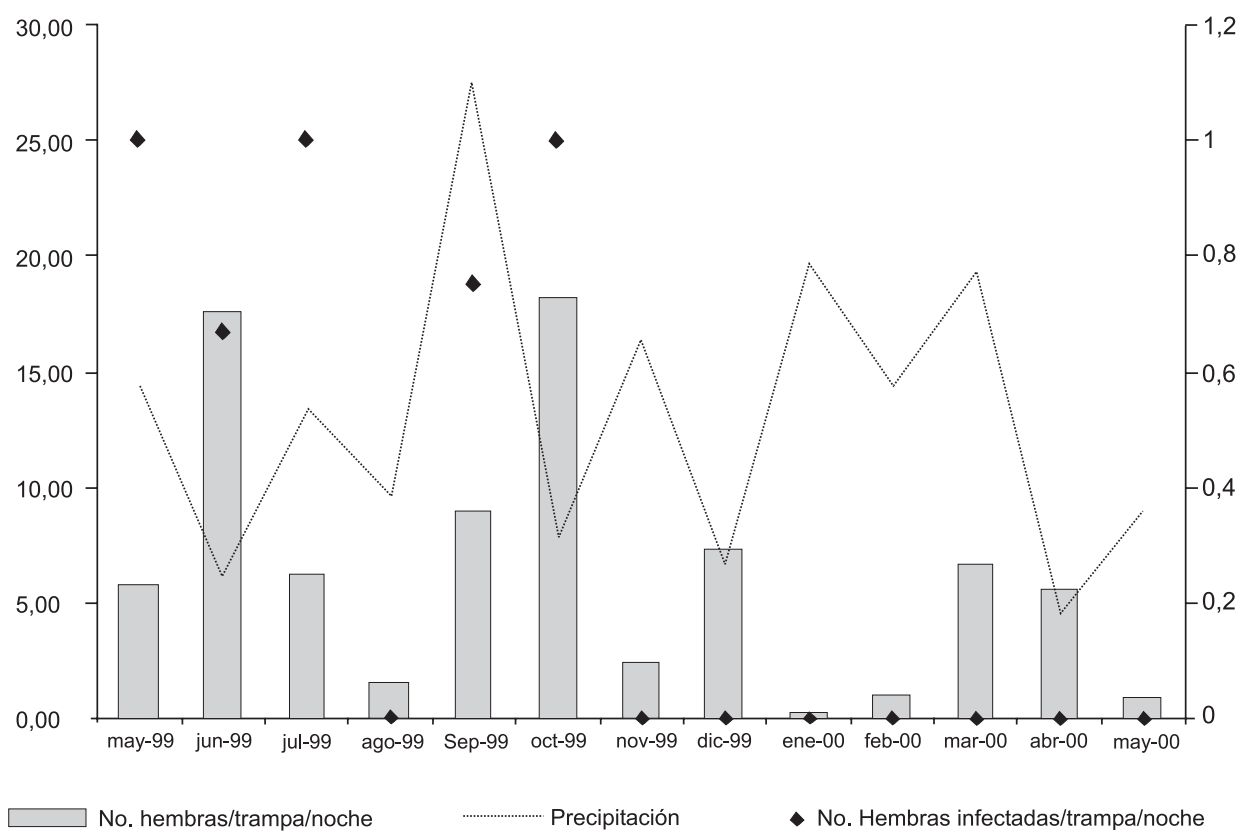

B

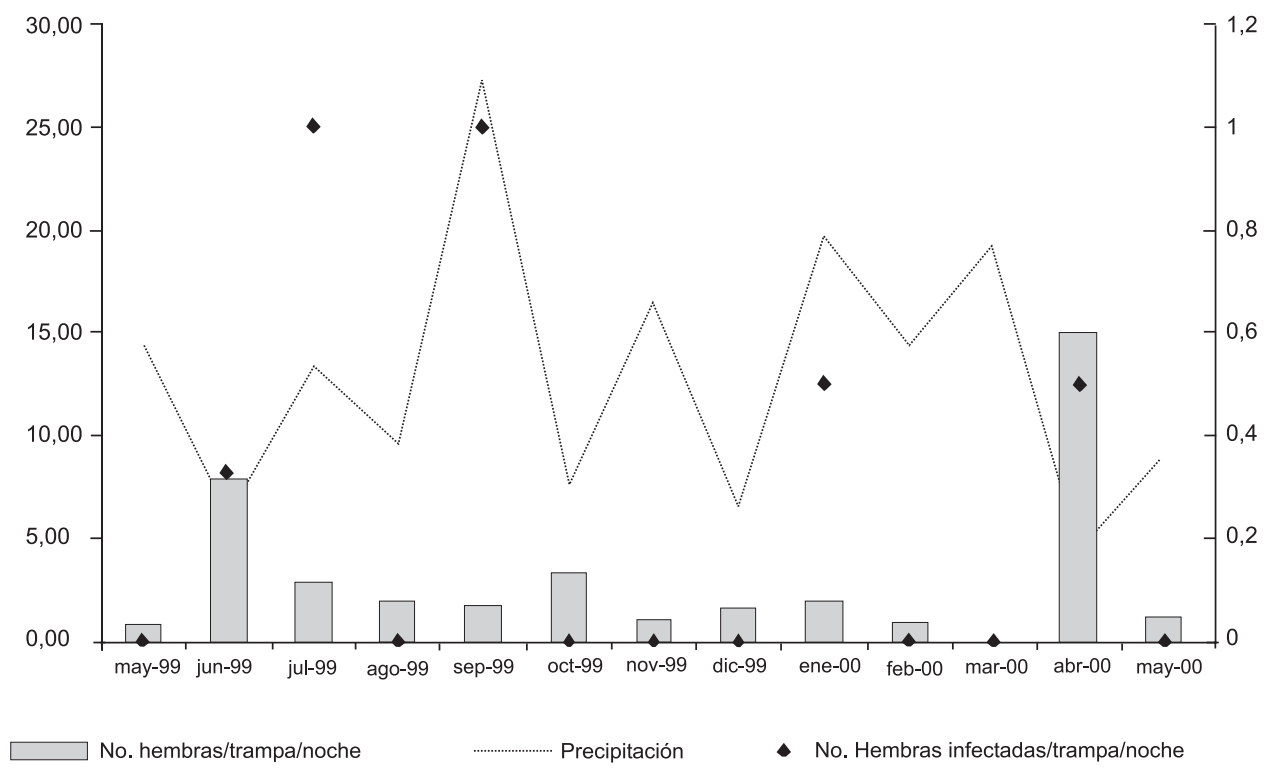

Figura 2. Abundancia estacional de hembras de Lutzomyia longipalpis capturadas en el intradomicilio (A) y peridomicilio (B) con trampas de luz CDC, de mayo de 1999 a mayo de 2000 Vs. abundancia de hembras de L. longipalpis encontradas naturalmente infectadas con Leishmania spp. y los valores mensuales de precipitación. 
captura (27,31); sin embargo, esta proporción fue menor que la observada en el intradomicilio por Sherlock y Guitton (27) lo que indica una presencia más representativa de las hembras en este lugar. En las capturas sobre cebo humano, gallina y perro, encontramos una mayor proporción de machos que de hembras. Similares resultados fueron hallados por Sherlock en el estado de Bahía, Brasil, utilizando como cebos cerdos, cabras y gallinas, difiriendo sólo en los resultados obtenidos sobre cebo humano, con el cual capturaron una mayor proporción de hembras (32).

Es bien conocido que el comportamiento alimentario de L. longipalpis es de carácter ecléctico, con un amplio rango de hospederos, que va desde animales silvestres y domésticos, hasta el hombre, pero mantiene un acentuado carácter zoofílico (33). En las capturas realizadas con aspiración directa sobre gallinas, perros y humanos se obtuvo un mayor número de $L$. longipalpis en el gallinero, lo cual sugiere tendencias por este tipo de cebo animal, que ya han sido observadas por otros autores (34); sin embargo, este hecho no se pudo evaluar por las características del foco de estudio, donde la presencia de gallineros no es generalizada.

L. longipalpis es capturada con frecuencia en grandes cantidades en el peridomicilio, probablemente, atraída por la presencia de animales domésticos, especialmente mamíferos grandes que, cuando escasean o están ausentes, le dan paso a las aves como los hospederos de elección $(24,33,35)$. Este comportamiento se observó en la localidad de estudio donde, debido a la ausencia de este tipo de animales, se observaron grandes cantidades de $L$. longipalpis en gallineros, pero contrastando con los otros focos, en los que mantiene también una alta presencia domiciliaria.

Algunos estudios sugieren que la entrada de $L$. longipalpis al domicilio humano ocurre cuando las condiciones climáticas o la falta de oportunidad del encuentro con hospederos para la ingestión de sangre en su hábitat natural son difíciles, obligándolas a incursionar dentro de las casas. Este comportamiento se observó al sur de Honduras donde se menciona la presencia de perros, pollos, cerdos y personas dentro de las viviendas durante el tiempo de recolección $(9,27)$, siendo ésta una condición favorable para $L$. longipalpis.

En Guatiguará, los humanos y los perros representan la mayor proporción de la biomasa total de vertebrados que atraen a las hembras, debido a la escasa disponibilidad de otros hospederos extradomiciliarios; esto se comprobó con los resultados obtenidos en las capturas con trampas de luz CDC; se observó una acentuada tendencia por el domicilio, estadísticamente significativa. Esto nos permite suponer que aunque, en general, $L$. longipalpis no es una especie particularmente antropofílica, en el caso particular de Guatiguará, el humano está entre sus principales hospederos.

Así mismo, los resultados de la dinámica de la infección natural en este ambiente permiten señalar que durante los meses de mayor abundancia (mayo a junio y septiembre a octubre), existe una correlación positiva con el ingreso de hembras infectadas al intradomicilo, lo cual sugiere que en esta época del año hay un mayor riesgo de transmisión de leishmaniosis visceral americana y que puede ocurrir en el ambiente domiciliario. Aunado a esto la alta tasa de infección natural registrada en las hembras capturadas sobre perro $(5,28 \%)$, señalan la importancia epidemiológica de este animal como una de las posibles fuentes de infección para L. longipalpis, como ha sido indicado en otras áreas de transmisión de leishmaniosis visceral (36) y comprobado en esta localidad por Márquez (14).

Por otro lado, la tasa total de infección natural de L. longipalpis obtenida a través de la técnica de PCR $(1,93 \%)$ se mantuvo en el rango registrado para áreas endémicas de leishmaniasis visceral de diversas regiones de Latinoamérica $(0,3 \%$ a $7,14 \%$ ), la mayoría de ellas obtenidas a través de examen directo $(3,5,7,22,29,35,37)$. Solamente el trabajo de Ryan y Brazil (35) presentó una tasa similar $(1,8 \%)$ a la encontrada en Guatiguará.

Diversos trabajos vienen utilizando la PCR como herramienta para la búsqueda de infección natural en focos de leishmaniasis cutánea (38-40); sin embargo, pocos estudios han aplicado esta 
técnica en áreas de leishmaniasis visceral, donde el principal vector es $L$. longipalpis, de manera tal que se puedan comparar las tasas mensuales de infección y su correlación con la dinámica poblacional de L. longipalpis, que permita confrontar los resultados obtenidos en Guatiguará.

La infección humana en la localidad de estudio, probablemente, ocurrió por la focalización y concentración de nuevos hospederos susceptibles en un ambiente enzoótico rural que, debido a las grandes modificaciones antrópicas, ocasionadas por la masiva migración humana, lo llevó a una situación de suburbanización y de transmisión de la leishmaniasis visceral en estas condiciones, en un área relativamente pequeña $\left(4 \mathrm{~km}^{2}\right)$.

La cercanía de esta localidad al área metropolitana de Bucaramanga, en especial al casco urbano del municipio de Piedecuesta, permite suponer un potencial riesgo de expansión de la leishmaniasis visceral a zonas cercanas de esta cabecera municipal que mantengan situaciones condicionantes que permitan el establecimiento de la leishmaniasis visceral. Las alteraciones en el ambiente rural y los constantes movimientos migratorios de la población hacia la periferia de las ciudades han demostrado que facilita el proceso de urbanización de la leishmaniasis visceral; en los últimos años se ha convertido en un creciente problema de salud pública (32,41-44).

Este estudio permitió demostrar que en Guatiguará se estableció un foco de leishmaniasis visceral con características suburbanas donde $L$. longipalpis está presente y es la especie más abundante. Esta especie presenta una tendencia acentuada hacia el intradomicilio, y es abundante en los meses secos como junio y octubre, cuando también se detectaron con frecuencia hembras de $L$. longipalpis infectadas naturalmente por Leishmania spp.

Teniendo en cuenta que el comportamiento de $L$. longipalpis es nocturno, que todos los casos se presentaron en niños menores de 7 años y que esta población, generalmente, está dentro de la casa en ese horario, el lugar de mayor riesgo de infección (microfoco) es el intradomicilio, por lo cual debe ser el sitio a donde se deben enfocar las medidas de prevención y control que permitan disminuir el contacto de los habitantes con el vector para así tener un impacto sobre la transmisión $(45,46)$.

\section{Agradecimientos}

A la Secretaría de Salud de Santander (funcionarios y técnicos del Programa de Enfermedades Transmitidas por Vectores); a las personas y a la comunidad de las viviendas del estudio por su colaboración durante las capturas de los flebótomos.

\section{Conflicto de intereses}

Los autores declaramos que no existe conflicto de interés.

\section{Financiación}

El presente estudio fue financiado por el Centro de Investigaciones en Enfermedades Tropicales, CINTROP-UIS, el Instituto Nacional de Salud, la Secretaría de Salud de Santander y la Alcaldía Municipal de Piedecuesta.

\section{Referencias}

1. Wilson ME, Streit JA. Visceral leishmaniasis Gastroenterol Clin North Am 1996;25:535-51.

2. Casas M, Angulo VM, Fajardo E. Kala-Azar en Colombia. Acta Med Colomb 1983;8:302-9.

3. Ferro C, Morrison AC, Torres M, Pardo R, Wilson M, Tesh RB. Species composition and relative abundance of sand flies of the genus Lutzomyia (Díptera: Psychodidae) at an endemic focus of visceral Leishmaniasis in Colombia. J Med Entomol 1995;32:527-37.

4. Travi BL, Montoya J, Gallego J, Jaramillo C, Llano R, Velez ID. Bionomics of Lutzomyia evansi (Diptera:Psychodidae) vector of visceral leishmaniasis in northern Colombia. J Med Entomol 1996;33:278-85.

5. Feliciangeli MD, Rodriguez N, De Guglielmo Z, Rodriguez A. The re-emergence of american visceral leishmaniasis in an old focus in Venezuela. II. Vectors and parasites. Parasite 1999;6:113-20.

6. Ferro C, Morales A. Flebótomos de Colombia: estudios realizados por el Laboratorio de Entomología 1965-1997. En: Toro G, Hernández CA, Raad J, editores. Instituto Nacional de Salud 1917-1997. Una historia, un compromiso. Santafé de Bogotá: Instituto Nacional de Salud; 1998. p.219-33.

7. Lainson R, Shaw JJ, Ryan L, Ribeiro RS, Silveira FT. Leishmaniasis in Brazil. XXI. Visceral leishmaniasis 
in the Amazon Region and further observations on the role of Lutzomyia longipalpis (Lutz \& Neiva, 1912) as the vector. Trans R Soc Trop Med Hyg 1985;79:223-6.

8. Uribe S. Polimorfismo entre poblaciones de Lutzomyia longipalpis, insecto transmisor de leishmaniasis visceral, sugiere la existencia de un complejo de especies. Biomédica 1999;19:56-66.

9. Carrasco J, Morrison A, Ponce C. Behaviour of Lutzomyia longipalpis in an area of southern Honduras endemic for visceral/ atypical cutaneous leishmaniasis. Ann Trop Med Parasitol 1998;92:869-76.

10. López Y, Osorio L, Álvarez G, Rojas J, Jiménez F, Gómez C et al. Sandfly Lutzomyia longipalpis in a cutaneous leishmaniasis focus in Central Colombia. Mem Inst Oswaldo Cruz 1996;91:415-9.

11. Ministerio de Salud. Guía integral de manejo de las enfermedades transmitidas por vectores malaria, dengue y leishmaniasis. Módulo 4. Santa Fe de Bogotá: Imprenta Nacional de Colombia; 1996.

12. Harris E, Kropp G, Belli A, Rodriguez B, Agabian N. Single step multiplex PCR assay for characterization of new world Leishmania complexes. J Clin Microbiol 1998;36:1989-95

13. Espinal LS. Zonas de vida o formaciones vegetales de Colombia. Memoria explicativa sobre el mapa ecológico. Bogotá: Instituto Geográfico Agustín Codazzi; 1978. p.238.

14. Márquez LL. Prevalencia de infección por Leishmania chagasi en la población canina (LVC) de la vereda Guatiguará de Piedecuesta, Santander (tesis). Bucaramanga: Universidad Industrial de Santander; 2004.

15. Marcondes CB. An improved technique for the dissection of female genitalia of phlebotomine sandflies (Diptera: Psychodidae), with an improvement in the handling of insects. Mem Inst Oswaldo Cruz 1998;93:109.

16. Young DG, Duncan MA. Guide to the identification and geographic distribution of Lutzomyia sand flies in Mexico, The West Indies, Central and South America (Diptera: Psychodidae). Mem Am Entomol Inst 1994; $54: 1-881$.

17. Belli A, Rodríguez B, Aviles H, Harris E. Simplified polymerase reaction chain detection of New World Leishmania in clinical specimens of cutaneous leishmaniasis. Am J Trop Med Hyg 1998;58:102-9.

18. Pirmez C, Da Silva Trajano V, Paes-Oliveira M, daCruz AM, Goncalves-da-Costa CS, Catanho M et al. Use of PCR in diagnosis of human american tegumentary leishmaniasis in Rio de Janeiro, Brazil. J Clin Microbiol 1999;37:1819-23.

19. Michalsky E, Fortes-Dias CL, Pimenta PF, Secundino NF, Dias ES. Assessment of PCR in the detection of Leishmania spp in experimentally infected individual phlebotomine sandflies (Diptera: Psychodidae: Phlebotominae). Rev Inst Med Trop Sao Paulo 2002;44:255-9.

20. Cabrera OL, Munstermann L, Cárdenas R, Gutiérrez $\mathbf{R}$, Ferro C. Definición de las condiciones de temperatura y almacenamiento adecuadas en la detección de ADN de Leishmania por PCR en flebotominos. Biomédica 2002; 22:296-302

21. Santamaría E, Castillo M, Cardenas R, Bello F, Ayala M, Ferro C. Transmisión experimental de Leishmania braziliensis a hámster por picadura de Lutzomyia longiflocosa (Diptera: Psychodidae) provenientes de un foco endémico en la zona cafetera colombiana. Medicas UIS 1998;12:279-84.

22. Le Pont F, Desjeux P. Leishmaniasis in Bolivia. I. Lutzomyia longipalpis (Lutz \& Neiva, 1912) as the vector of visceral leishmaniasis in Los Yungas. Trans $\mathrm{R}$ Soc Trop Med Hyg 1985;79:227-31.

23. Lainson R, Shaw J, Silveira FT, Fraiha H. Leishmaniasis in Brazil. XIX: visceral leishmaniasis in the Amazon Region, and the presence of Lutzomyia longipalpis on the Island of Marajó, Pará State. Trans R Soc Trop Med Hyg 1983;77:323-30.

24. Ximenes MF, De Souza M, Castellon E. Density of sand flies (Diptera:Psychodidae) in domestic and wild animal shelters in an area of visceral leishmaniasis in the state of Rio Grande do Norte, Brazil. Mem Inst Oswaldo Cruz 1999;94:427-32.

25. Zeledón R, Murillo J, Gutiérrez H. Observaciones sobre la ecología de Lutzomyia longipalpis (Lutz \& Neiva, 1912) y posibilidades de existencia de leishmaniasis visceral en Costa Rica. Mem Inst Oswaldo Cruz 1984;79:455-9.

26. Rebelo JM, Leonardo FS, Costa JM, Pereira YN, Silva FS. Sandflies (Diptera, Psychodidae) from an endemic leishmaniasis area in the cerrado region of the State of Maranhão, Brazil. Cad Saude Publica 1999;15:623-30.

27. Sherlock I, Guitton N. Observacoes sobre calazar em Jacobina, Bahia-III- Algunos dados sobre o Phlebotomus longipalpis, o principal transmissor. Rev Bras Malariol Doencas Trop 1969;21:541-8.

28. Moreno G, Oviedo M. Bionomy of vector of American Visceral Leishmaniasis in Trujillo, State, Venezuela. II Longitudinal study of Lutzomyia evansi in endemic situation. Bol Dir Malariol Saneam Amb 1995;35:359-70.

29. Ryan I, Silveira FT, Lainson R, Shaw JJ. Leishmanial infections in $L$. longipalpis and $L$. antunesi (Diptera: Psychodidae) on the island of Marajó, Pará State, Brazil. Trans R Soc Trop Med Hyg 1984;78:547-8.

30. Santos SO, Arias J, Ribeiro AA, Paiva H, Freitas M, Malacco RA. Incrimination of Lutzomyia cruzi as a vector of american visceral leishmaniasis. Med Vet Entomol 1998;12:315-7. 
31. Morrison A, Ferro C, Pardo R, Torres M, Wilson M, Tesh RB. Nocturnal activity patterns of Lutzomyia longipalpis (Diptera: Psychodidae) at an endemic focus of visceral leishmaniasis in Colombia. J Med Entomol 1995;32:605-17.

32. Sherlock I. Ecological interactions of visceral leishmaniasis in the state of Bahia, Brazil. Mem Inst Oswaldo Cruz 1996;91:671-83.

33. Morrison AC, Ferro C, Tesh RB. Host preferences of the sand fly Lutzomyia longipalpis at an endemic focus of american visceral leishmaniasis in Colombia. Am J Trop Med Hyg 1993;49:68-75.

34. Dias Fde O, Lorosa ES, Rebêlo JM. Blood feeding sources and peridomiciliation of Lutzomyia longipalpis (Lutz \& Neiva, 1912) (Psychodidae, Phlebotominae). Cad Saude Publica 2003;19:1373-80.

35. Ryan L, Brazil RP. Leishmania infections in Lutzomyia longipalpis (Diptera:Psychodidae) on the island of Sao Luis, Maranhao State, Brazil. Mem Inst Oswaldo Cruz 1984;79:383-4.

36. Marzochi MC, Marzochi KB, Carvalho RW. Visceral leishmaniasis in Rio de Janeiro. Parasitol Today 1994; 10:37-40.

37. Corredor A, Gallego JF, Tesh RB, Morales A, De Carrasquilla FC, Young DG et al. Epidemiology of visceral leishmaniasis in Colombia. Am J Trop Med Hyg 1989;40:480-6.

38. Pérez E, Ogusuku E, Inga R, Lopez M, Moje J, Paz L et al. Natural leishmania infection of Lutzomyia spp in Peru. Trans R Soc Trop Med Hyg 1994;88:161-4.

39. Rodríguez N, Aguilar CM, Barrios MA, Barker DC. Detection of Leishmania braziliensis in naturally infected individual sand flies by polymerase chain reaction. Trans R Soc Trop Med Hyg 1999;93:47-9.

40. Jorquera A, González R, Marchán-Marcano E, Oviedo M, Matos M. Multiplex-PCR for detection of natural Leishmania infection in Lutzomyia spp. captured in an endemic region for cutaneous leishmaniasis in state of Sucre, Venezuela. Mem Inst Oswaldo Cruz 2005; 100:45-8.

41. Silva ES, Gontijo CM, Pacheco RS, Fiuza VO, Brazil RP. Visceral leishmaniasis in the Metropolitan Region of Belo Horizonte, State of Minas Gerais, Brazil. Mem Inst Oswaldo Cruz 2001;96:285-91.

42. WHO. Control of leishmaniases. Report of a WHO Expert Committee. Technical Report Series, $N^{\circ} 793$. Geneva: World Health Organization; 1990.

43. Bejarano EE, Uribe $S$, Rojas W, Vélez ID. Phlebotomine sand flies (Diptera:Psychodidae) associated with the appearance of urban leishmaniasis in the city of Sincelejo, Colombia. Mem Inst Oswaldo Cruz 2002; $97: 645-7$.

44. Agudelo LA, Uribe J, Sierra D, Ruíz F, Vélez ID. Presence of american cutaneous leishmaniasis vectors surrounding the city of Medellín, Colombia. Mem Inst Oswaldo Cruz 2002;975:641-2.

45. Feliciangeli MD, Mazzarri MB, Blas SS, Zerpa 0. Control trial of Lutzomyia longipalpis s.I in the Island of Margarita, Venezuela. Trop Med Int Health 2003;8: 1131-6.

46. Maroli M, Khoury C. Prevention and control of leishmaniasis vectors: current approaches. Parassitologia 2004:46:211-5 